\title{
Review of Management of Type-2 Odontoid Fracture in Elderly
}

\section{Jagodish Chandra Ghosh}

National Institute of Traumatology and Orthopedic Rehabilitation (NITOR), Dhaka, Bangladesh

Email:drghoshjc@gmail.com

How to cite this paper: Ghosh, J.C. (2021) Review of Management of Type-2 Odontoid Fracture in Elderly. Open Journal of Orthopedics, 11, 12-21.

https://doi.org/10.4236/ojo.2021.111002

Received: February 9, 2020

Accepted: January 23, 2021

Published: January 26, 2021

Copyright $\odot 2021$ by author(s) and Scientific Research Publishing Inc. This work is licensed under the Creative Commons Attribution International License (CC BY 4.0).

http://creativecommons.org/licenses/by/4.0/

\begin{abstract}
Odontoid fracture accounts for $15 \%-20 \%$ of all cervical spine injuries. Among the odontoid fracture, type- 2 fracture is the most common variety. This injury is associated with a high incidence of morbidity, mortality and nonunion in the elderly irrespective of mode of treatment. Management of odontoid fracture cannot be standardized till to date and ideal treatment for type- 2 odontoid fractures still has some controversial issues. Objective of this review is to find a controversial aspect of management along with opinion to find out a standard guideline by searching the literature in Pubmed and Google scholar databases with key words: odontoid, fracture, type-2, management, nonoperative and operative management. Nonoperative treatment with halo vest is associated with very high rate of complication in elderly patient. When conservative treatment of this fractures is indicated that should be carried out with hard cervical collar or cervicothoracic orthosis. Current studies suggest that surgical management of odontoid fractures may offer a protective benefit but it is limited to patients younger than 75 years of age. Though surgical treatment has a better outcome, it is also limited by the co-mobidities and hazards of anesthesia and surgery in elderly patients. Conservative treatment of this fracture in the elderly should preferably be carried out with hard collar or avoiding halo vest. Surgical treatment is associated with little advantage but should be selected with proper attention to age, comorbidities, fracture geometry and it is better to individualize the treatment strategy.
\end{abstract}

\section{Keywords}

Odontoid, Fracture, Type-2, Management, Review

\section{Introduction}

Odontoid fracture accounts for approximately $15 \%-20 \%$ of all fractures of 
cervical spine. They represent the most common cervical spine injury of patient older than 70 years [1] [2]. Odointoid fracture has a bimodal distribution involving early childhood and the elderly age group [3] [4] [5]. In young adults, the fractures occur most often due to high energy trauma including motor vehicle crashes and in the elderly with low energy trauma commonly due to fall from standing height [6] [7]. The mechanism responsible for odontoid fracture is generally accepted to be hyper-flexion or hyper-extension of cervical spine. In contrast to younger age group, elderly patients had predominantly type-2 fractures [7]. Type-2 odontoid fractures have been associated with limited healing potential, as the original report by Anderson and D'Alonzo [8]. Several other authors have also reported a high rate of nonunion in type-2 fractures [9]-[14]. While there is no consensus on why these fractures are difficult to heal, hypotheses include vascular insult, odontoid morphology and ligamentous forces [15]. Elderly patients with type- 2 odontoid fracture are also associated with a high rate of mortality, regardless of intervention [16]. Because of age related comorbidities and ubiquitous presence of degenerative changes in the aging cervical spine, elderly patients are at higher risk for complications and poorer outcomes than younger patients sustaining similar injuries [17]-[23]. Besides degenerative changes, odontoid fractures in the elderly seem to be an osteoporotic fracture and the poor outcome is also contributed by higher rate of communition at the fracture site. Decreased $\mathrm{BMD}$ is a major predisposing factor for the occurrence of traumatic osteoporotic fractures in the elderly [24] [25].

Despite their frequency, there is considerable ambiguity regarding optimal management strategies for these fractures in the elderly. In elderly people, poor bone health and medical co-morbidities contribute to increased surgical risk, however, nonoperative management is associated with risk of complications like nonunion or fibrous union [26]. In most countries of the world, the elderly are the most rapidly growing segment of society and it is estimated that by 2025 almost a fifth of the population will be over the age of 65 [26]. The incidence of odontoid fractures is likely to increase in future throughout the world as longevity of people is increasing.

The treatment of odontoid fracture in the elderly requires surgeons to balance considering patients' medical comorbidities and surgical morbidity and mortality against the high rate of nonunion occurring with conservative management. Surgeon with experiences in this field knows that surgical outcome can as easily be adverse as it can be beneficial [27].

\section{Objective}

Aim of present study is to evaluate literature and find out the strategy which can be adopted in managing type- 2 odontoid fracture in elderly until evidence based protocol or standard guideline can be established.

\section{Materials and Methods}

A systematic computerized literature search was performed using PubMed, 
Google Scholar databases. The searches were performed using medical subject heading terms and the subheadings used were Fracture, Odontoid, type-2, operative, management, nonoperative. No language restrictions were used. Articles were taken into account irrespective of date of publication.

During screening of databases relevant and topic appropriate articles were selected. All article related to this topic found in databases cannot be taken into account. Data regarding type-2 odontoid fracture in elderly were not analysed separately.

For effective data extraction search can be performed reviewing larger number of article from the data base along with use of specific headings and subheadings.

\section{Results}

Classification of odontoid fracture:

The most commonly used classification system for odontoid fractures is that of Anderson and D'Alaonzo classification. This classification divides odontoid fractures into 3 types: type-1fractures through the tip of the odontoid (due to avulsion of the alar and apical ligaments), type-2-fractures at the base of the odontoid, and type- 3 fractures extending from the base of the odontoid into the vertebral body. This classification had a significant impact on prognosis. Type-2 fractures had a $36.3 \%$ nonunion rate a sharp contrast to type- 3 fractures $(7.6 \%$ nonunion rate) and type- 1 fractures ( $0 \%$ nonunion rate) [8].

Overview of odontoid fracture

Patho-anatomy of odontoid fractures: Several anatomical and morphological studies have described the trabecular anatomy of the odontoid process [28] [29] [30]. These traditionally divide odontoid process into 3 structurally distinct regions: the tip, the body and the base [31]. As patients age increases, there is relatively larger reduction in bone density at the odontoid base relative to the remainder of axis. The structural weakness of the odontoid base coupled with increased bone loss due to age may underlie the high rate of odontoid fractures in the geriatric population [29].

Nonoperative treatment options

Halo vest orthosis: Halo vest was first developed by Perry and Nickel for stabilization of patients with poliomyelitis. Over the last few decades it has undergone several modifications in design and materials with consequent expansion of its indications. Presently it offers an advantage over other cervical orthosis in terms of limitation of movement in upper cervical spine [32]. Several authors have preffered its use but many others have suggested a more cautious approach for its use in elderly quoting morbidity and mortality of up to $51 \%$ and $40 \%$ respectively. More recently, DePass et al. reported $11.1 \%$ hospital mortality rate for geriatric patients who had halo vest application for odontoid fracture treatment [33]. In a series of 78 patients (mean age 80) treated for odontoid fracture with surgery, halo vest or a cervical collar it was found that patient treated with a Ha- 
lo vest were over 4 times more likely to have pneumonia (34\% vs $8 \%$ ), 5 times more likely to suffer cardiac arrest, and twice as likely to have any complication as the non Halo vest cohort [34]. Other minor complications following halo vest include pin site infection, loose pin, neck pain, decreased range of motion, thoracic skin ulcers and dysphagia.

Cervical Collar Immobilization: Soft collars have no stabilizing function and not recommended to use in early phase of treatment for odontoid fractures. However they may be used for nonoperative treatment in stable fracture fractures after an initial phase with a hard collar. Hard collars (Philadelphia for example) may be used in the first phase for unstable fractures until a decision for further treatment is made. It may be used for 6 to 8 weeks in cases where nonoperative treatment is indicated. Odontoid fractures may also be treated using cervicothoracic braces (Minerva). Using this strategy of treatment, success for type-2 odontoid fractures also averages just under $75 \%$. While cervical collars are generally well tolerated without a risk for serious adverse events, the increased motion may theoretically increase the risk of nonunion. Unfortunately the data comparing cervical collars to halo-vest are of poor quality. Odontoid nonunion and instability are high in geriatric patients treated with a rigid cervical collar. Fracture healing and stability did not correlate with improved outcomes. and outcomes did not differ significantly from age-matched cohorts [35].

Surgical treatment of odontoid fracture:

The surgical stabilization of an odontoid fracture may be done either using an anterior odontoid screw fixation or a posterior C1 C2 fusion. Anterior odontoid screw fixation has the advantage of preserving atlanto-axial motion and is minimally invasive in terms of the exposure and muscle damage [36]. In elderly patients surgical treatment of type- 2 odontoid fractures is justified by the excellent fusion rate which allows the patients to quickly regain their pre-injury autonomy. The risks associated with anterior fixation of odontoid with screws are directly related to indications and surgical techniques [37] [38]. Posterior surgical stabilization has evolved from posterior wiring and clamps to transarticular screws and subsequent $\mathrm{C} 1-\mathrm{C} 2$ instrumentation with screw plate and screw-rod system. The posterior procedure can provide strong fixation and high rate of bone healing, however the sacrifice of atlanto-axial function is inevitable [39]. However the selection of surgical procedure remains controversial, specially in the geriatric population. Currently anterior screw fixation has been a popular surgical treatment. The reported success rates have been relatively high, averaging $94.5 \%$ with a low complication rate of implant related complications and and very low rate of neurovascular injury [40]. Posterior fusion is also associated with excellent fusion rate but should be reserved for patients in whom odontoid screw fixation either fails or not feasible [41]. Posterior transarticular C1/2 stabilization and fusion technique first described by Jeanneret and Magerl [42]. The classical posterior fusion technique with bone graft is perfomed by an open approach. This technique may be modified into a percutaneous cannulated posterior C1/2 stabilization. Posterior instrumentation (Harms/Goel), C1/2 internal 
fixation by placing $\mathrm{C} 1$ lateral mass screw and $\mathrm{C} 2$ pedicle screws according to Harms/Goel is a valuable alternative to the Margerl technique. Posterior Occipito- Cervical Stabilization and Fusion (C0 - C3/4): The presence of ankylosing spondylitis, diffuse idiopathic skeletal hyperostosis or complex injuries may alter the treatment algorithm and a C1/2 stabilization alone may be insufficient. In these cases, an occipito-cervical stabilization and fusion may be performed.

\section{Discussion}

Elderly patients with a fracture of odontoid are a high risk group with high morbidity and mortality. Treatment options of odontoid fractures vary from conservative management with external immobilization by cervical collar, Minerva, halo orthosis and other cervicothoracic orthoses to operative management with anterior odontoid fixation or posterior cervical fusion with or without supplemental screw fixation [43]. It is evident that each treatment option has a role and that the management has to be individualized. When considering the optimal treatment for type- 2 odontoid fracture in the elderly, several factors need to be taken into consideration including medical co-morbidities, healing potential of the fracture, anticipated tolerance of halovest or surgery and patient wishes [44] [45] [46]. The concept of ideal treatment for type-2 odontoid fracture in the elderly is that treatment which would provide the best possible functional outcome with least associated risk and not simply the best radiological outcome alone. While it is true that osseous union is a measureable absolute outcome measure, the views of several authors that the stable fibrous union may be an adequate aim of treatment in elderly, cannot be ignored.

Conservative treatment has the advantage to avoid anesthesia and surgical risk but associated with elevated risk of nonunion. Age and co-morbidities influence mortality and medical complication rate most, regardless of fracture type and treatment of choice. Pseudoarthrosis represents the main complication, the incidence of which increases with age. Stable type-2 odontoid fracture can be successfully treated with nonrigid immobilization even if they are displaced. But unstable injuries of odontoid are a hazard to every elderly person, since associated dysphagia and respiratory restrictions are potentially dreadly complications [47]. It is important to adopt an aggressive diagnostic approach to detect unstable fracture. To evaluate stability of the fracture, lateral flexion /extension views or dynamic fluoroscopy are mandatory and should be repeated after several days.

With advancing age there is relatively larger reduction in bone density at the base of odontoid relative to the remainder of axis. There is also a difference in fracture personality in geriatric patients as compared to the younger patients. Elderly people are also being commonly associated with medical comobidities. Odontoid nonunion and instability are high in geriatric patients treated with a rigid cervical collar. Halo vest is associated with high rate of complications like nonunion, pneumonia, respiratory complications. In one study it was reported that there were complication rates of pneumonia (34\%), cardiac arrest (26\%), 
and mortality (42\%) in elderly patients treated with a halo vest [48]. Current evidence suggests that when conservative treatment of this fracture is indicated that should be carried out with a hard cervical collar or cervicothoracic orthosis [49]. Unfortunately the data comparing cervical collars to halo-vest are of poor quality.

Surgical treatment provides a high rate of union but limited by the age related co-morbidity and risk of anesthesia. Recently it has been argued by some studies that surgical treatment is associated with increased longevity. In light of these observations, controversy again came in the field regarding the optimal management of odontoid fractures in elderly [50]. Though some authors have advocated aggressive surgical stabilization in these patients, citing an increased fusion or fracture healing rate and decreased morbidity and mortality while other reports have not shown a significant advantage for surgery versus nonoperative management. Mortality risk increases with advancing patient's age and the number of co-morbidities. It is difficult to evaluate the effect of surgery on mortality because of selection bias. With this limitation in mind the data suggest that surgery may offer a protective benefit in patients younger than 75 years of age. The result of one study suggest that surgical intervention was associated with reduced mortality for individuals aged 65 to 74 years and to a less extent those patients aged 75 to 84 years. Although such association decreases as patients age increases, only $21 \%$ of those treated surgically had died at 1 -year postinjury compared with $36 \%$ of the individual managed nonoperatively [51]. Type- 2 odontoid fractures after decades of clinical research and development of different surgical strategies are still a management challenge. In a recent work by Donnally et al. after scrolling through 394,260 articles pertaining to odontoid fractures, no evidence based management algorithm can be proposed [52].

\section{Limitation of the Study}

1) Separate analysis of data regarding type-2 fracture and elderly patients was not possible.

2) Chance of adoption of advanced search technique application was limited.

\section{Conclusion}

There is no evidence based management protocol or standard guideline has yet been developed for managing odontoid fracture in the elderly. The incidence of odontoid fractures is likely to increase in future throughout the world as longevity of people is increasing. All modalities of management are associated with quite high rate of morbidity and mortality. In planning treatment of odontoid type-2 fracture, the fracture pattern, dislocation, severity of displacement, stability of the fracture, the particular age of the patient, patient co-morbidity and patient wishes should be taken into account. It is important to individualize the treatment strategy. Further research is recommended to solve such a complex and ever increasing problem. 


\section{Conflicts of Interest}

There is no conflict of interest in this study.

\section{References}

[1] Scheyerer, M.J., Zimmermann, S.M., Simmen, H.P., Wanner, G.A. and Werner, C.M. (2013) Treatment Modality in Type 2 Odontoid Fracture Defines the Outcome in Elderly Patients. BMC Surgery, 13, 54. https://doi.org/10.1186/1471-2482-13-54

[2] Bronson, W.H. and Protopaltis, T. (2013) Management of Type-2 Odontoid Fracture in Adults. Bulletin of the Hospital for Joint Diseases, 77, 4-10.

[3] Bohlman, H.H. (1979) Acute Fractures and Dislocations of the Cervical Spine. An Analysis of Three Hundred Hospitalized Patients and Review of the Literature. The Journal of Bone and Joint Surgery. American Volume, 61, 1119-1142. https://doi.org/10.2106/00004623-197961080-00001

[4] Hadley, M.N., Dickman, C.A., Browner, C.M. and Sonntag, V.K. (1989) Acute Axis Fractures: A Review of 229 Cases. Journal of Neurosurgery, 71, 642-647. https://doi.org/10.3171/jns.1989.71.5.0642

[5] Hanigan, W.C., Powell, F.C., Elwood, P.W. and Henderson, J.P. (1993) Odontoid Fractures in Elderly Patients. Journal of Neurosurgery, 78, 32-35. https://doi.org/10.3171/jns.1993.78.1.0032

[6] Ivancic, P.C. (2014) Odontoid Fracture Biomechanics. Spine (Phila Pa 1976), 39, E1403-E1410. https://doi.org/10.1097/BRS.0000000000000609

[7] Muller, E.J., Wick, M., Russe, O. and Muhr, G. (1999) Management of Odontoid Fractures in Elderly. European Spine Journal, 8, 360-365. https://doi.org/10.1007/s005860050188

[8] Anderson, L.D. and D'Alonzo, R.T. (1974) Fractures of the Odontoid Process of the Axis. The Journal of Bone and Joint Surgery. American Volume, 56, 1663-1674. https://doi.org/10.2106/00004623-197456080-00017

[9] Clark, C.R. and White, A.A. (1985) Fractures of the Dens. A Multricenter Study. The Journal of Bone and Joint Surgery. American Volume, 67, 1340-1348. https://doi.org/10.2106/00004623-198567090-00006

[10] Hart, R., Saterbak, A., Rapp, T. and Clark, C. (2000) Nonoperative Management of Dens Fracture Nonunion in Elderly Patient without Myelopathy. Spine, 25, 1339-1343. https://doi.org/10.1097/00007632-200006010-00004

[11] Harrop, J.S., Przybylski, G.J., Vaccaro, A.R. and Yalamanchili, K. (2000) Efficacy of Anterior Odontoid Screw Fixation in Elderly Patients with Type-2 Odontoid Fractures. Neurosurgical Focus, 8, e6. https://doi.org/10.3171/foc.2000.8.6.7

[12] Platzer, P., Thalhammer, G., Sarahrudi, K., Kovar, F., Vecsei, V. and Gaebler, C. (2007) Nonoperative Management of Odontoid Fractures Using a Halothoracic Vest. Neurosurgery, 61, 522-530. https://doi.org/10.1227/01.NEU.0000290898.15567.21

[13] Vaccaro, A.R., Kepler, C.K., Kopjar, B., Chapman, J., Shaffrey, C., Amold, P., Gokaslan, Z., et al. (2013) Functional and Quality of Life Outcomes in Geriatric Patients with Type-2 Dens Fracture. The Journal of Bone and Joint Surgery. American Volume, 95, 729-735. https://doi.org/10.2106/JBJS.K.01636

[14] Govender, S. and Grootboom, M. (1988) Fractures of the Dens the Results of Nonrigid Immobilization. Injury, 19, 165-167.

https://doi.org/10.1016/0020-1383(88)90007-1 
[15] Amling, M., Hahn, M., Wening, V.J., Grote, H.J. and Delling, G. (1994) The Microarchitecture of the Axis as the Predisposing Facture for Fracture of the Base of the Odontoid Process. A Histomorphometric Analysis of Twenty-Two Autopsy Specimens. The Journal of Bone and Joint Surgery. American Volume, 76, 1840-1846. https://doi.org/10.2106/00004623-199412000-00011

[16] Schoenfeld, A.J., Bono, C.M., Reichmann, W.M., Warholic, N., Wood, K.B., Losina, E., et al. (2011) Type II Odontoid Fractures of the Cervical Spine-Do Treatment Type and Medical Comorbidities Affect Mortality in Elderly Patients? Spine (Phila Pa 1976), 36, 879-885. https://doi.org/10.1097/BRS.0b013e3181e8e77c

[17] Chutkan, N.B., King, A.G. and Harris, M.B. (1997) Odontoid Fracture: Evaluation and Management. The Journal of the American Academy of Orthopaedic Surgeons, 5, 199-204. https://doi.org/10.5435/00124635-199707000-00003

[18] Spivak, J.M., Weiss, M.A., Cotler, J.M. and Call, M. (1994) Cervical Spine Injuries in Patients 65 and Older. Spine, 19, 2302-2306. https://doi.org/10.1097/00007632-199410150-00009

[19] Platzer, P., Thalhammer, G., Ostermann, R., Wieland, T., Vecsesi, V. and Gaebler, C. (2007) Anterior Screw Fixation of Odontoid Fractures Comparing Younger and Elderly Patients. Spine, 32, 1714-1720. https://doi.org/10.1097/BRS.0b013e3180dc9758

[20] Frangen, T.M., Zilkens, C., Muhr, G. and Schinkel, C. (2007) Odontoid Fractures in the Elderly: Dorsal C1/C2 Fusion Is Superior to Halo-Vest Immobilization. The Journal of Trauma, 63, 83-89. https://doi.org/10.1097/TA.0b013e318060d2b9

[21] Malik, S.A., Murphy, M., Connolly, P. and O’Byme, J. (2008) Evaluation of Morbidity, Mortality and Outcome Following Cervical Spine Injuries in Elderly Patients. European Spine Journal, 17, 585-591. https://doi.org/10.1007/s00586-008-0603-3

[22] Gornet, M.E. and Kelly, M.P. (2016) Fracture of the Axis: A Review of Pediatric, Adult and Geriatric Injuries. Current Reviews in Musculoskeletal Medicine, 9, 505-512. https://doi.org/10.1007/s12178-016-9368-1

[23] Pepin, J.W., Bourne, R.B. and Hawkins, R.J. (1985) Odontoid Fractures, with Special Reference to the Elderly Patient. Clinical Orthopaedics and Related Research, 193, 178-183. https://doi.org/10.1097/00003086-198503000-00025

[24] Osti, M., Philipp, H., Meusburger, B. and Benedetto, K.P. (2011) Analysis of Failure Following Anterior Screw Fixation of Type-2 Odontoid Fracture in Geriatric Patients. European Spine Journal, 20, 1915. https://doi.org/10.1007/s00586-011-1890-7

[25] Watanabe, M., Sakai, D., Yamamoto, Y., Nagai, T., Sato, M. and Mochida, J. (2014) Analysis of Predisposing Factors in Elderly People with Type-2 Odontoid Fractures. The Spine Journal, 14, 861-866. https://doi.org/10.1016/j.spinee.2013.07.434

[26] Hagen, S. (1999) CBO Memorandum: Projections and Expenditures for Long Term Care Services for the Elderly. Congressional Budget Office, Washington DC.

[27] Lyer, S., Hurlbert, R.J. and Albert, T.J. (2018) Management of Odontoid Fractures in the Elderly: A Review of the Literature and an Evidence-Based Treatment Algorithm. Neurosurgery, 82, 419-430. https://doi.org/10.1093/neuros/nyx546

[28] Korres, D.S., Karachalios, T., Roidis, N., Lycomitros, V., Spiliopoulou, C.A. and Lyritis, G. (2004) Structural Properties of the Axis Studied in Cadaveric Specimens. Clinical Orthopaedics and Related Research, 418, 134-140. http://www.ncbi.nlm.nih.gov/pubmed/15043104 https://doi.org/10.1097/00003086-200401000-00021

[29] Amling, M., Posl, M., Wening, V.J., Ritzet, H., Hahn, M. and Delling, G. (1995) 
Structural Heterogeneity within the Axis: The Main Cause in the Etiology of Dens Fractures. Journal of Neurosurgery, 83, 330-335. https://doi.org/10.3171/jns.1995.83.2.0330

[30] Heller, J.G., Alson, M.D., Schaffler, M.B. and Garfin, S.R. (1992) Quantitative Internal Dens Morphology. Spine, 17, 861-866.

http://www.ncbi.nlm.nih.gov/pubmed/1523487 https://doi.org/10.1097/00007632-199208000-00001

[31] Heggeness, M.H. and Doherty, B.J. (1993) The Trabecular Anatomy of the Axis. Spine, 18, 1945-1949. http://www.ncbi.nlm.nih.gov/pubmed/8272940 https://doi.org/10.1097/00007632-199310001-00003

[32] Johnson, R., Hart, D. and Simmons, E. (1977) Cervical Orthoses: A Study Comparing Their Effectiveness in Restricting Cervical Motion in Normal Subjects. The Journal of Bone and Joint Surgery. American Volume, 59, 332-339. https://doi.org/10.2106/00004623-197759030-00007

[33] DePasse, J.M., Palumbo, J.A., Ahmad, A.K., Adams, C.A. and Daniels, A.H. (2017) Halo-Vest Immobilization in Elderly Odontoid Fracture Patients: Evaluation in the Treatment Modality and In-Hospital Outcomes. Clinical Spine Surgery, 30, E1206-E1210. https://doi.org/10.1097/BSD.0000000000000483

[34] Sharpe, J.P., Magnotti, L.J., Weinberg, J.A., Schroeppel, T.J., Fabian, T.C. and Croce, M.A. (2016) The Old Man and the C-Spine Fracture: Impact of Halo Vest Stabilization in Patients with Blunt Cervical Spine Fractures. Journal of Trauma and Acute Care Surgery, 80, 76-80. https://doi.org/10.1097/TA.0000000000000894

[35] Molinari, R.W., Khera, O.A., Gruhn, W.L. and McAssey, R.W. (2012) Rigid Cervical Collar Treatment for Geriatric Type-2 Odontoid Fractures. European Spine Journal, 21, 855-862. https://doi.org/10.1007/s00586-011-2069-y

[36] Rajasekaran, S., Kamath, V. and Avadhani, A. (2010) Odontoid Anterior Screw Fixation. European Spine Journal, 19, 339-340. https://doi.org/10.1007/s00586-010-1305-1

[37] Collins, I. and Min, W.K. (2008) Anterior Screw Fixation of Type-2 Odontoid Fractures in the Elderly. The Journal of Trauma, 65, 1083-1087. https://doi.org/10.1097/TA.0b013e3181848cbc

[38] Apfelbaum, R.I., Lonser, R.R., Veres, R. and Casey, A. (2009) Direct Anterior Screw Fixation for Recent and Remote Odontoid Fractures. Journal of Neurosurgery, 93, 227-236. https://doi.org/10.3171/spi.2000.93.2.0227

[39] Harms, J. and Melcher, R.P. (2001) Posterior C1-2 Fusion with Polyaxial Screw and Rod Fixation. Spine, 26, 2467-2471. https://doi.org/10.1097/00007632-200111150-00014

[40] Korres, D.S., Chytas, D.G., Markatos, K.N., Efstathopoulos, N.E. and Nikolaou, V.S. (2017) The "Challenging" Fractures of the Odontoid Process: A Review of the Classification Schemes. European Journal of Orthopaedic Surgery \& Traumatology, 27, 469-475. https://doi.org/10.1007/s00590-016-1895-3

[41] Sawarkar, D.P., Singh, P.K., Siddique, S.A., Agrawal, D., Satyarthee, G.D., Gupta, D.K., Sinha, S., Kale, S.S. and Sharma, B.S. (2015) Surgical Management of Odontoid Fractures at Level One Trauma Center: A Single Center Series of 142 Cases. Neurology India, 63, 40-48. https://doi.org/10.4103/0028-3886.152633

[42] Jeanneret, B. and Magerl, F. (1992) Primary Posterior Fusion C1/2 in Odontoid Fracture: Indications, Technique and Results of Transarticular Screw Fixation. Journal of Spinal Disorders, 5, 464-475. https://doi.org/10.1097/00002517-199212000-00012 
[43] Joaquim, A.F. and Patel, A.A. (2015) Surgical Treatment of Type-2 Odontoid Fractures: Anterior Odontoid Screw Fixation or Posterior Cervical Instrumented Fusion? Neurosurgical Focus, 38, E11. https://doi.org/10.3171/2015.1.FOCUS14781

[44] Anderson, S., Rodrigues, M. and Olerud, C. (2000) Odontoid Fractures: High Complication Rate Associated with Anterior Screw Fixation in the Elderly. European Spine Journal, 9, 56-59. https://doi.org/10.1007/s005860050009

[45] Bednar, D.A., Parikh, J. and Hummel, J. (1995) Management of Type-2 Odontoid Process Fracture in Geriatric Patients: A Perspective Study of Sequential Cohorts with Attention to Survivorship. Journal of Spinal Disorders, 8, 166-169. https://doi.org/10.1097/00002517-199504000-00013

[46] Yang, Z., Yuan, Z.Z., Ma, J.X. and Ma, X.L. (2015) Conservative versus Surgical Treatment for Type-2 Odontoid Fractures in the Elderly: Grading the Evidence through a Meta-Analysis. Orthopaedics \& Traumatology: Surgery \& Research, 101, 839-844. https://doi.org/10.1016/j.otsr.2015.08.011

[47] Mekata, K., Takigawa, T., Matsubayashi, J., Toda, K., Hasegawa, Y. and Ito, Y. (2016) The Effect of the Cervical Orthosis on Swallowing Physiology and Cervical Spine Motion during Swallowing. Dysphagia, 31, 74-83.

https://doi.org/10.1007/s00455-015-9660-Z

[48] Tashjian, R.Z., Majercik, S., Biffl, W.L., Palumbo, M.A. and Cioffi, W.G. (2006) Halo-Vest Immobilization Increases Early Mobidity and Mortality in Elderly Odontoid Fractures. The Journal of Trauma, 60, 199-203. https://doi.org/10.1097/01.ta.0000197426.72261.17

[49] Carvalho, A.D., Fiqueiredo, J., Schroeder, G.D., Vaccaro, A.R. and Rodriques-Pinto, R. (2019) Odontoid Fractures: A Critical Review of Current Management and Future Directions. Clinical Spine Surgery, 32, 313-323. https://doi.org/10.1097/BSD.0000000000000872

[50] Majercik, S., Tashjian, R.Z., Biffl, W.L., Harrington, D.T. and Cioffi, W.G. (2005) Halo Vest Immobilization in the Elderly: A Death Sentence? The Journal of Trauma, 59, 350-357. https://doi.org/10.1097/01.ta.0000174671.07664.7c

[51] Muller, E.J., Wick, M., Russe, O. and Muhr, G. (1999) Management of Odontoid Fractures in the Elderly. European Spine Journal, 8, 360-365.

https://doi.org/10.1007/s005860050188

[52] Donnally, C.J., Trapana, E.J., Barnhill, S.W., Bondar, K.J., Rivera, S., Sheu, J.I. and Wang, M.Y. (2019) The Most Influential Publications in Odontoid Fracture Management. World Neurosurgery, 123, 41-48.

https://doi.org/10.1016/j.wneu.2018.11.205 